LAWRENCE LIVERMORE N A T IO N A L LABORATORY

\title{
Actinide measurements by accelerator mass spectrometry at Lawrence Livermore National Laboratory
}

T. A. Brown, A. A. Marchetti, R. E. Martinelli, C. C. Cox, J. P. Knezovich, T. F. Hamilton

October 29, 2003

9th International Conference on Accelerator Mass Spectrometry Nagoya, Japan September 9, 2002 through September 13, 2002 
This document was prepared as an account of work sponsored by an agency of the United States Government. Neither the United States Government nor the University of California nor any of their employees, makes any warranty, express or implied, or assumes any legal liability or responsibility for the accuracy, completeness, or usefulness of any information, apparatus, product, or process disclosed, or represents that its use would not infringe privately owned rights. Reference herein to any specific commercial product, process, or service by trade name, trademark, manufacturer, or otherwise, does not necessarily constitute or imply its endorsement, recommendation, or favoring by the United States Government or the University of California. The views and opinions of authors expressed herein do not necessarily state or reflect those of the United States Government or the University of California, and shall not be used for advertising or product endorsement purposes. 
Paper for submission to the

Proceedings of the

9th International Conference on Accelerator Mass Spectrometry.

Nagoya University, Nagoya, Japan, September 9-13, 2002.

Authors: $\quad$ T.A. Brown”, A.A. Marchetti ${ }^{\mathrm{b}}$, R.E. Martinelli ${ }^{\mathrm{b}}$, C.C. Cox J.P. Knezovich ${ }^{\mathrm{a}}$, T.F. Hamilton ${ }^{\mathrm{b}}$

${ }^{a}$ Center for Accelerator Mass Spectrometry L-397, Lawrence Livermore National Laboratory, Livermore CA USA

${ }^{\mathrm{b}}$ Environmental Science Division, Lawrence Livermore National Laboratory, Livermore CA USA

Title:

Actinide measurements by accelerator mass spectrometry at Lawrence Livermore National Laboratory 
Reference \#: $\quad$ O14B-6

Title: Actinide measurements by accelerator mass spectrometry at Lawrence Livermore National Laboratory

Authors: $\quad$ T.A. Brown ${ }^{\mathrm{a},}$, A.A. Marchetti ${ }^{\mathrm{b}}$, R.E. Martinelli ${ }^{\mathrm{b}}$, C.C. Cox $^{\mathrm{b}}$, J.P. Knezovich ${ }^{\mathrm{a}}$, T.F. Hamilton ${ }^{\mathrm{b}}$

Affiliations:

a Center for Accelerator Mass Spectrometry L-397, Lawrence Livermore National Laboratory, Livermore CA USA

b Environmental Science Division, Lawrence Livermore National Laboratory, Livermore CA USA

† Corresponding author. Phone: 925423 8507. email: tabrown@1lnl.gov .

Corresponding Author: Thomas A. Brown

Mailing Address: $\quad$ Center for Accelerator Mass Spectrometry

POB 808, L-397

Livermore, CA 94550 USA

Phone: $\quad 9254238507$

FAX: $\quad 9254237884$

email: $\quad$ tabrown@llnl.gov

PACS: $\quad$ 29.17.+w, 29.30.Aj, 41.75.-i, 41.75.Cn 32.10.Bi, 07.75.+h, 82.55.+e, 82.80.Ms

Keywords: $\quad$ Plutonium, Actinides, Actinide elements, radiochemistry, Plutonium bioassay, Trace detection, Accelerator mass spectrometry (AMS)

\begin{abstract}
We report on the development of an accelerator mass spectrometry (AMS) system for the measurement of actinides at Lawrence Livermore National Laboratory. This AMS system is centered on a recently completed heavy isotope beam line that was designed particularly for high sensitivity, robust, high-throughput measurements of actinide concentrations and isotopic ratios. A fast isotope switching capability has been incorporated in the system, allowing flexibility in isotope selection and for the quasi-continuous normalization to a reference isotope spike.

Initially, our utilization of the heavy isotope system has concentrated on the measurement of $\mathrm{Pu}$ isotopes. Under current operating conditions, background levels equivalent to $\sim 1 \mathrm{X} 10^{5}$ atoms are observed during routine ${ }^{239} \mathrm{Pu}$ and ${ }^{240} \mathrm{Pu}$ measurements. Measurements of samples containing $\sim 10{ }^{13}{ }^{238} \mathrm{U}$ atoms demonstrate that the system provides a ${ }^{238} \mathrm{U}$ rejection factor during ${ }^{239} \mathrm{Pu}$
\end{abstract}


measurements of $\sim 10^{7}$. Measurements of known materials, combined with results from an externally organized inter-comparison program, indicate that our ${ }^{239} \mathrm{Pu}$ measurements are accurate and precise down to the $\mu \mathrm{Bq}$ level $\left(\sim 10^{6}\right.$ atoms $)$. Recently, we have investigated the performance of our heavy isotope AMS system in measurements of ${ }^{237} \mathrm{~Np}$ and ${ }^{236} \mathrm{U}$. Results of these investigations are discussed. The sensitivity shown by our $\mathrm{Pu}$ measurements, combined with the high throughput and interference rejection capabilities of our AMS system, demonstrate that AMS can provide a rapid and cost-effective measurement technique for actinides in a wide variety of studies. 


\section{Introduction}

Accelerator mass spectrometry (AMS) has been demonstrated for the ultra-sensitive measurement of concentrations and isotope ratios for several actinides [e.g., 1-6]. As an actinide measurement technique, AMS has several desirable attributes including high efficiency, high rejection of interferences, low susceptibility to matrix components, and large dynamic range. In the practical application of the AMS technique, these attributes provide a number of advantages over other actinide measurement techniques. As an example, our experiences indicate that these advantages allow routine ultra-sensitive $\mathrm{Pu}$ isotope measurements with reduced demands on sample preparation chemistry, which is a limiting factor in the routine application of some other actinide concentration and isotope ratio measurement methods [7]. When combined with demonstrated capabilities of AMS systems, the application of AMS techniques to the ultrasensitive measurement of actinides offers the possibility of high sample throughput and rapid analyses while maintaining low detection sensitivities of $\lesssim 1 \times 10^{6}$ atoms per sample for several actinides, including the plutonium isotopes ${ }^{239,240,241,242,244} \mathrm{Pu}$.

The development of the heavy isotope AMS system at Lawrence Livermore National Laboratory's (LLNL) Center for Accelerator Mass Spectrometry (CAMS) was undertaken with particular interest in the measurement of actinides in environmental samples, including air filters, soil, sediment, water, marine biota, and human urine. Further, low-level measurements of $\mathrm{Pu}$ isotopes, ${ }^{236} \mathrm{U}$ and ${ }^{237} \mathrm{~Np}$ all have a number of applications in the fields of nuclear isotopic forensics, risk assessments for occupational and long-term environmental stewardship, and litigation over occupational, military and/or public exposures. In this paper we describe the current actinide measurement system at CAMS and present results obtained for selected plutonium, neptunium and uranium isotopes. The initial Phase I configuration of the system was presented at AMS-8 [3], and our description of the current system will emphasize the modifications and improvements to the system that have occurred in completing Phase II of the actinide measurement system. 


\section{AMS-based actinide measurements at LLNL}

\subsection{Actinide Beamline}

The completed Phase II configuration of the actinide measurement system at CAMS is shown in Figure 1. The main modifications from the Phase I configuration are 1) the installation of the $45^{\circ}$ cylindrical electrostatic analyzer (ESA) (in place of the Phase I Wien filter), 2) the shift of the image slits of the $30^{\circ}$ Analyzing Magnet downstream to about 4-m distance, and 3) the installation of fast-switching electrostatic deflector plates at the exit of the $30^{\circ}$ analyzing magnet.

(Fig. 1)

The actinide spectrometer has been designed to fully resolve neighboring isotopes at 250 amu and to reject interferences from mass " $\mathrm{m}-1$ " ions having the same magnetic rigidity as the mass " $m$ " ions of interest; e.g., the electrostatic analyzer will reject ${ }^{238} \mathrm{U}^{5+}$ ions with the same magnetic rigidity as the ${ }^{239} \mathrm{Pu}^{5+}$ ions of interest. The fast-switching electrostatic deflector plates at the exit of the $30^{\circ}$ analyzing magnet were installed to enable fast isotope switching of the actinide spectrometer. This fast isotope switching capability, coupled with the fast mass switching capability of the low energy mass spectrometer, allows flexibility in isotope selection and the quasi-continuous normalization to a reference isotope spike. In routine measurements the fast isotope switching capability currently allows automated cycling between measurements of up to 4 isotopes, with each being quasi-continuously normalized to measurements of a reference isotope. 


\subsection{Sample Preparation}

The sample preparation methods used are based on the standard protocols used for alpha spectrometry in the US DOE Marshall Islands Program [8], with the additional final steps necessary to provide a sample form appropriate for AMS. These steps involve combining aliquots of prepared sample solutions, typically containing about $10^{9}-10^{11} \mathrm{Pu}$ atoms, with aliquots of solutions containing about $0.3 \mathrm{mg}$ of $\mathrm{Fe}(\mathrm{III})$ and $\mathrm{Nb}(\mathrm{V})$, which is needed to coprecipitate the relatively few atoms of $\mathrm{Pu}$ into a manageable amount of precipitate. The precipitate is converted to oxide form by baking at $800^{\circ} \mathrm{C}$. The resulting oxide powder is then pressed into a standard LLNL aluminum AMS sample holder. For most measurements a reference isotope spike (e.g., ${ }^{242} \mathrm{Pu}$ ) is added to samples prior to digestion for isotope normalization. For some measurements, previously measured sample concentrations of particular isotopes are used to provide the reference isotope.

\subsection{AMS Measurements}

With the completion of the Phase II configuration, the operating conditions for routine actinide measurements have changed significantly from those described for the Phase I configuration [3]. With the present measurement system, $40 \mathrm{keV}$ negative oxide ions (e.g., ${ }^{239-244} \mathrm{Pu}^{16} \mathrm{O}^{-}$and ${ }^{238} \mathrm{U}^{16} \mathrm{O}^{-}$) are produced from the samples using a cesium sputter source [9] and then energy-selected by the $90^{\circ}$ spherical ESA. Using fast switching of the potential of the insulated vacuum box, the $90^{\circ}$ injection magnet provides fast-switched alternation of the injected ion mass between that of ions of interest (e.g. ${ }^{239} \mathrm{Pu}^{16} \mathrm{O}^{-}$) and that of reference isotope ions (e.g., ${ }^{242} \mathrm{Pu}^{16} \mathrm{O}^{-}$). The actinide spectrometer is set to transport $5+$ ions at $39 \mathrm{MeV}$ energy to the detector, with the reference isotope being selected at the $30^{\circ}$ analyzing magnet image slits with the mass-selecting deflector plates set to zero volts. The selection of ions of interest is accomplished by electrostatic deflection of the desired ions through the image slits. Cycling between an isotope of interest and the reference isotope is synchronized with alternation of the 
injected ion mass. Under current automated measurement operations, ions of interest from a sample (e.g., ${ }^{239} \mathrm{Pu}^{5+}$ ) are counted for $0.4 \mathrm{sec}$ followed by measurement of the reference ions (e.g., ${ }^{242} \mathrm{Pu}^{5+}$ ) for $0.1 \mathrm{sec}$; cycling is continued for $10 \mathrm{sec}$. After measurement of one isotope of interest the mass-selecting electrostatic settings are shifted to those appropriate for another isotope of interest (e.g., ${ }^{240} \mathrm{Pu}^{5+}$ ) and cycling is repeated. A two-anode, longitudinal field gas ionization detector is used for ion detection; the detector has sufficient resolution to allow clean rejection of interfering ions at $4+$ and lower charge states. Based on total numbers of ions detected from samples prepared from a known number of isotope atoms, the total measurement efficiency (sample preparation and AMS measurement) is $\sim 5 \times 10^{-5}$.

\section{Results}

\subsection{Plutonium Measurements}

Following completion of the Phase II installation, our efforts have concentrated on the measurement of $\mathrm{Pu}$ isotopes. To evaluate the performance of our measurement system and develop routine operating conditions for $\mathrm{Pu}$ measurements, we have routinely prepared and measured replicate samples derived from a calibrated ${ }^{239} \mathrm{Pu}$ solution (IPL 630-22-3). These calibration samples normally span the expected ${ }^{239} \mathrm{Pu}$ concentration range of the unknown samples. The calibration samples also contain a reference isotope spike (usually ${ }^{242} \mathrm{Pu}$ ) at a concentration that is typical of the spike level in the unknown samples. Results from a routine set of such samples are shown in Fig. 2.

\section{(Fig. 2)}

Analyses of IPL-based calibration samples and blank (background) samples indicate a background for routine measurements equivalent to $1 \mathrm{X} 10^{5}{ }^{239} \mathrm{Pu}$ atoms and a limit of detection 
of $5 \times 10^{5}{ }^{239} \mathrm{Pu}$ atoms [10]. These analyses also indicate that there is little or no scatter in the AMS measurements above that due to counting statistics based uncertainties. Measurements of IPL calibration samples spanning the range from $<10^{6}$ to $>10^{11}{ }^{239} \mathrm{Pu}$ and/or ${ }^{242} \mathrm{Pu}$ atoms have demonstrated a dynamic range of at least 5 orders of magnitude.

As a part of our routine evaluation of $\mathrm{Pu}$ measurement system performance we also measure blank (background) samples containing $10^{13}{ }^{238} \mathrm{U}$ atoms. These measurements provide an indication of the effectiveness of the AMS system in rejecting ${ }^{238} \mathrm{U}$ interferences in the measurement of ${ }^{239} \mathrm{Pu}$. The results demonstrate a rejection factor of $>10^{7}$ during routine ${ }^{239} \mathrm{Pu}$ measurements. This high rejection of ${ }^{238} \mathrm{U}$ interferences allows samples (including environmental samples) to be prepared for ultra-sensitive $\mathrm{Pu}$ measurement using the relatively simple chemical procedures developed to prepare samples for routine alpha spectroscopy measurements.

Additionally, we routinely measure samples of traceable $\mathrm{Pu}$ isotopic standards CRM 128 $\left({ }^{239} \mathrm{Pu} /{ }^{242} \mathrm{Pu}=0.9993 \pm 0.0003\right)$ and $\mathrm{CRM} 138\left({ }^{240} \mathrm{Pu} /{ }^{239} \mathrm{Pu}=0.0863 \pm 0.0001\right)$. These measurements are intended as monitors for mass-dependent normalization factors for our ${ }^{239} \mathrm{Pu}$, ${ }^{240} \mathrm{Pu}$ and ${ }^{242} \mathrm{Pu}$ isotope measurements. Under our routine operating conditions, the measured ratios are generally accurate within their uncertainties and show no evidence of mass-dependent biases. For example, the weighted mean value of $0.0858 \pm 0.0006 \pm 0.0009$ ( \pm weighted mean uncertainty \pm weighted-standard-deviation-based uncertainty in the mean) obtained for the AMS measured ${ }^{240} \mathrm{Pu} /{ }^{239} \mathrm{Pu}$ ratios for 35 CRM 138 samples prepared and measured between March and October, 2002 (Fig. 3) is consistent with the certified atom ratio for this standard (given above).

(Fig. 3)

Our concentration on the measurement of $\mathrm{Pu}$ isotopes has been driven, in part, by the need of the US DOE Marshall Islands Program for low-level measurements of $\mathrm{Pu}$ isotopes in human urine samples. To obtain an independent evaluation of our capabilities for the low-level 
measurement of $\mathrm{Pu}$ in human urine, we participated in the "Second Laboratory Intercomparison Study for the Determination of $\mu \mathrm{Bq}$ Quantities of ${ }^{239} \mathrm{Pu}$ in Synthetic Urine by Mass Spectrometric and Fission Track Analyses" [11]. The ${ }^{239} \mathrm{Pu}$ results obtained by AMS measurement at LLNL for the NIST prepared synthetic urine samples are shown in Fig. 4.

(Fig. 4)

Subsequent to submission of measurement results by all participating laboratories, the study organizers provided information on the isotopic contents of the synthetic urine samples and the results of preliminary statistical analyses. The samples had been prepared at ${ }^{239} \mathrm{Pu}$ levels of 56 , 29, 9.2, 3.7 and $0 \mu \mathrm{Bq}$, and ${ }^{240} \mathrm{Pu}$ had been added at the global fallout ${ }^{240} \mathrm{Pu} /{ }^{239} \mathrm{Pu}$ ratio of $\sim 0.15$ to yield samples with ${ }^{240} \mathrm{Pu}$ levels of $32,16,5.2,2.1$ and $0 \mu \mathrm{Bq}$ for corresponding ${ }^{239} \mathrm{Pu}$ levels. Uranium was also added to the samples at a level (0.05 Bq per sample) that approximated the background level observed in human urine samples from the vicinity of Los Alamos, NM. Based on the information provided by the study organizers the samples were grouped according to prepared levels (5 samples at each level) and the following average values were obtained: NIST: $56 \mu \mathrm{Bq}$ - LLNL AMS: $55.1 \pm 1.7 \pm 1.8 \mu \mathrm{Bq}$; NIST: $29 \mu \mathrm{Bq}$ - LLNL AMS: $28.2 \pm 1.0 \pm$ $0.7 \mu \mathrm{Bq}$; NIST: $9.2 \mu \mathrm{Bq}$ - LLNL AMS: $8.09 \pm 0.54 \pm 0.40 \mu \mathrm{Bq}$; NIST: $3.7 \mu \mathrm{Bq}$ - LLNL AMS: $3.28 \pm 0.30 \pm 0.47 \mu \mathrm{Bq}$. The statistical analyses of the results obtained by AMS at LLNL indicate that the scatter of the measured values is consistent with the uncertainty estimates of the measurements and that the measured values are accurate within the measurement uncertainties. The AMS measurements met the ANSI 13.30 criteria for precision and bias at all sample levels. Application of the methodology of Currie[12] to the LLNL AMS results produces minimum detectable amount (MDA) estimates for these synthetic urine samples of $0.82 \mu \mathrm{Bq}$ for ${ }^{239} \mathrm{Pu}$ and $2.1 \mu \mathrm{Bq}$ for ${ }^{240} \mathrm{Pu}$. Significantly, $\mathrm{U}$ in samples did not have a discernible impact on the precision and accuracy of the AMS measurements. Hence, the high ${ }^{238} \mathrm{U}$ rejection provided by the AMS system allows the utilization of routine, relatively simple sample preparation chemistry in 
preparing samples containing significant amounts of $\mathrm{U}$ for ${ }^{239} \mathrm{Pu}$ and ${ }^{240} \mathrm{Pu}$ measurement at $\mu \mathrm{Bq}$ levels.

\subsection{Neptunium Measurements}

Recently, we have investigated the performance of our heavy isotope AMS system for measurements of ${ }^{237} \mathrm{~Np}$. For these measurements, samples with equal ${ }^{239} \mathrm{Pu}$ and ${ }^{237} \mathrm{~Np}$ atom content which spanned the range from $10^{6}$ to $10^{10}$ atoms were prepared; these samples also contained $3 \times 10^{9}{ }^{242} \mathrm{Pu}$ atoms as the reference isotope. These samples were measured with automated cycling between ${ }^{239} \mathrm{Pu},{ }^{240} \mathrm{Pu}$ and ${ }^{237} \mathrm{~Np}$ and fast-isotope-switching normalization to the ${ }^{242} \mathrm{Pu}$ reference isotope throughout the measurements.

Comparison of the numbers of detected ${ }^{237} \mathrm{~Np}$ and ${ }^{239} \mathrm{Pu}$ ions for individual samples containing identical numbers of the two isotopes indicates that the actinide measurement system efficiency for ${ }^{237} \mathrm{~Np}$ is lower than for Pu isotopes. The lower efficiency for ${ }^{237} \mathrm{~Np}(\sim 0.65)$ is roughly consistent with the relative probability for the formation of ${ }^{237} \mathrm{NpO}^{-}$ions with respect to ${ }^{242} \mathrm{PuO}^{-}$ions of $0.77 \pm 0.03$ given by Fifield et al. [2]. The difference in efficiencies for Np and $\mathrm{Pu}$ isotopes precludes the calculation of ${ }^{237} \mathrm{~Np}$ atom contents based on normalization to the ${ }^{242} \mathrm{Pu}$ reference isotope spike. For the purposes of this study, the measured ${ }^{237} \mathrm{~Np} /{ }^{242} \mathrm{Pu}$ ratios for the samples have been normalized to the average ${ }^{237} \mathrm{~Np} /{ }^{242} \mathrm{Pu}$ ratio for the samples containing $10^{10}$ ${ }^{237} \mathrm{~Np}$ atoms. The renormalized results (Fig. 5) indicate that the Phase II configuration of the actinide measurement system is capable of measuring samples ranging in ${ }^{237} \mathrm{~Np}$ content from $<10^{6}$ to $>10^{10}$ atoms. The limited number of ${ }^{237} \mathrm{~Np}$ measurements of blank samples (containing only the ${ }^{242} \mathrm{Pu}$ reference isotope spike) indicate that the measurement background is likely to be equivalent to $<0.5 \times 10^{6}{ }^{237} \mathrm{~Np}$ atoms.

(Fig. 5) 


\subsection{Uranium Measurements}

We have also recently investigated the performance of our heavy isotope AMS system in the measurement of $U$ isotopes, particularly ${ }^{236} U$. For these measurements, a set of calibration samples were prepared with ${ }^{236} \mathrm{U}$ contents which spanned the range from $\sim 10^{5}$ to $\sim 10^{8}$ atoms. In addition, sets of blank/background samples and of samples containing $\sim 10^{13}{ }^{238} \mathrm{U}$ atoms from a natural uranium solution were prepared. All of the samples contained $2 \times 10^{9}{ }^{233} \mathrm{U}$ atoms as the reference isotope. For the ${ }^{236} \mathrm{U}$ spiked samples and the blank samples automated cycling was set to measure only ${ }^{236} \mathrm{U}$, with fast-isotope-switching normalization to the ${ }^{233} \mathrm{U}$ reference isotope. The natural uranium samples were measured with automated cycling between ${ }^{236} U,{ }^{235} \mathrm{U}$ and ${ }^{234} \mathrm{U}$, with fast-isotope-switching to the ${ }^{233} \mathrm{U}$ reference isotope.

(Fig. 6)

Comparison of the measured ${ }^{236} \mathrm{U}$ contents of the calibration curve samples to the expected contents (Fig. 6) indicates that the actinide measurement system at CAMS is capable of measuring samples ranging in ${ }^{236} \mathrm{U}$ content from $\sim 10^{5}$ to $\sim 10^{8}$ atoms. The results obtained for other U, Np and Pu isotopes discussed above indicate that the measurement system's upper limit is, in fact, $>10^{11}{ }^{236} \mathrm{U}$ atoms, with the limit probably due to detector/electronics dead-time and response limitations. The results obtained for the blank/background samples produced only limiting estimates of the ${ }^{236} \mathrm{U}$ measurement background because no ${ }^{236} \mathrm{U}$ ions were detected during the measurement of those samples. In conjunction with the results obtained for the lowest level calibration curve samples ( $8.6 \times 10^{4}{ }^{236} \mathrm{U}$ atoms), the blank/background sample results indicate that the limit of detection is $\sim 10{ }^{5}{ }^{236} \mathrm{U}$ atoms.

The ${ }^{235} \mathrm{U} /{ }^{233} \mathrm{U}$ and ${ }^{234} \mathrm{U} /{ }^{233} \mathrm{U}$ results obtained for the samples containing $\sim 10^{13}{ }^{238} \mathrm{U}$ atoms allowed the determination of the AMS measured ${ }^{234} U /{ }^{235} U$ ratio of the natural uranium spike; the calculated value of $0.0076 \pm 0.0004$ is consistent with the expected ratio for natural uranium of 
0.00774. The ${ }^{235} \mathrm{U} /{ }^{233} \mathrm{U}$ result, coupled with the known ${ }^{235} \mathrm{U} /{ }^{238} \mathrm{U}$ ratio of natural uranium and the known ${ }^{233} \mathrm{U}$ reference spike, allowed the determination of the ${ }^{238} \mathrm{U}$ atoms in the prepared natural uranium samples. The obtained value of $(5.2 \pm 0.1) \times 10^{12}{ }^{238} \mathrm{U}$ atoms is consistent (cf. $\sim 10^{13}$ ${ }^{238} \mathrm{U}$ atoms expected) with the roughly estimated concentration of this isotopic ratio standard.

\section{Conclusions}

The Phase II development of the actinide measurement system at CAMS has been recently completed and the results obtained to date demonstrate that the design goals of developing a high sensitivity, high throughput AMS system for the measurement of actinide concentrations and isotope ratios have been realized. The improved mass resolution and rejection of interferences provided by the relocation of the $30^{\circ}$ analyzing magnet image slits downstream and the installation of the $45^{\circ}$ cylindrical ESA have significantly reduced the measurement background levels. The fast isotope switching capability allows automated measurements over a range of isotopes, great flexibility in isotope selection, and the quasi-continuous normalization to a reference isotope.

Results obtained from measurements of certified $\mathrm{Pu}$ reference materials, and from participation in the externally organized NIST inter-comparison study, demonstrate that measured ${ }^{239} \mathrm{Pu}$ and ${ }^{240} \mathrm{Pu}$ levels are accurate and precise down to the $\mu \mathrm{Bq}$ level $\left(\sim 10^{6}\right.$ atoms $)$. Measurements of blanks show that background levels during routine ${ }^{239} \mathrm{Pu}$ and ${ }^{240} \mathrm{Pu}$ measurements are equivalent to $\sim 1 \mathrm{X} 10^{5}$ atoms, and measurements of ${ }^{238} \mathrm{U}$-spiked samples demonstrate that the system provides a ${ }^{238} \mathrm{U}$ rejection factor during ${ }^{239} \mathrm{Pu}$ measurements of $\sim 10^{7}$. Results obtained during exploratory measurements of ${ }^{237} \mathrm{~Np}$ and ${ }^{236} \mathrm{U}$ indicate that these isotopes can be measured routinely using the Phase II system. The initial results show a dynamic measurement range of at least 5 orders of magnitude for both isotopes and demonstrate background levels equivalent to $<0.5 \times 10^{6}$ atoms for ${ }^{237} \mathrm{~Np}$ and a limit of detection for ${ }^{236} \mathrm{U}$ of $\sim 10^{5}$ atoms. 
With the establishment of routine operational conditions, the combination of components of the Phase II actinide measurement system now allows the AMS measurement of plutonium concentrations/isotope ratios for $>40$ unknown samples within a $24-\mathrm{h}$ period. The combination of this high throughput capability with the relatively routine and simple chemical procedures for the preparation of samples permitted by the AMS system's high rejection of interferences has allowed the development of an ultra-sensitive AMS-based actinide measurement system with a demonstrated capability for rapid and cost-effective measurements of $\mathrm{Pu}, \mathrm{U}$ and $\mathrm{Np}$ isotopes. 


\section{Acknowledgements}

The authors thank Dr. J.E. McAninch for guiding the initial phases of development of the heavy isotope measurement system. We thank D. McCurdy, Duke Engineering and Services, and Z. Lin and K. Inn, NIST, for organizing the intercomparison exercise on $\mathrm{Pu}$ in synthetic urine. This work was funded, in part, through the U.S. Department of Energy Marshall Islands Program, Office of Health Studies EH-6, and Office of Nonproliferation and National Security NN-20, and the LLNL Research and Development Program (99-ERD-033). This work was

performed under the auspices of the U. S. Department of Energy by the University of California, Lawrence Livermore National Laboratory under Contract No. W-7405-Eng-48. 


\section{References}

[1] L.K. Fifield, R.G. Cresswell, M.L. Ditada, T.R. Ophel, J.P. Day, A.P. Clacher, S.J. King, N.D. Priest, Nucl. Instr. Meth. B 117, 1996, 295.

[2] L.K. Fifield, A.P. Clacher, K. Morris, S.J. King, R.G. Cresswell, J.P. Day, and F.R. Livens, Nucl. Instr. Meth. B 123, 1997, 400.

[3] J.E. McAninch et al., Nucl. Instr. Meth. B 172, 2000, 711.

[4] O.J. Marsden, F.R. Livens, J.P. Day, L.K. Fifield, P.S. Goodall, Analyst 126, 2001, 633.

[5] C. Vockenhuber, I. Ahmad, R. Golser, W. Kutschera, V. Liechtenstein, A. Priller, P. Steier, S. Winkler, International J. of Mass Spec. 223-224, 2003, 713.

[6] X-L. Zhao, M-J. Nadeau, L.R. Kilius, A.E. Litherland, Nucl. Instr. Meth. B 92, 1994, 249.

[7] J.E. McAninch, T.F. Hamilton, Measurement of plutonium and other actinides at the Center for Accelerator Mass Spectrometry: A comparative assessment of competing techniques, Lawrence Livermore National Laboratory, Report No. UCRL-ID-133118, 1999.

[8] K.M. Wong, T. Jokela, V.E. Noshkin, Radiochemical procedures for analysis of Pu, Am, Cs, and $\mathrm{Sr}$ in water, soil, sediments and biota samples, Lawrence Livermore National Laboratory, Report No. UCRL-ID-116497, 1994.

[9] J. Southon, M. Roberts, Nucl. Instr. Meth. B 172, 2000, 257.

[10] K.T. Bogen, A.A. Marchetti, T.A. Brown, Nucl. Instr. Meth. B XXX, 200X, XXX (these proceedings).

[11] A.A. Marchetti, T.A. Brown, J.E. McAninch, J. Brunk, C.C. Cox, R.E. Martinelli, J.P. Knezovich, T.F. Hamilton, Measurements of Plutonium Isotopes in Urine at Microbecquerel Levels: AMS Results of a NIST Interlaboratory Exercise, Lawrence Livermore National Laboratory, Report No. UCRL-ID-147972, 2002.

[12] L.A. Currie, Anal. Chem. 40, 1968, 586. 


\section{Figure Captions}

Fig. 1. AMS actinides measurement system at LLNL. The current system reflects the completion of Phase II of the system development. The isotope resolving capability of the high energy Actinide Spectrometer is provided by the analyzing magnet $\left(30^{\circ}\right.$ magnetic bend, image slits $4 \mathrm{~m}$ downstream) and the electrostatic analyzer (cylindrical, $4.4 \mathrm{~m}$ radius, $5 \mathrm{~cm}$ plate gap, $45^{\circ}$ bending angle, $50 \mathrm{kV} / \mathrm{cm}$ maximum field).

Fig. 2. Measured 239Pu concentrations of a typical set of routine samples prepared from IPL 630-22-3.

Fig. 3. Measured ${ }^{240} \mathrm{Pu} /{ }^{239} \mathrm{Pu}$ ratios of $35 \mathrm{CRM} 138$ samples prepared and measured between March and October, 2002.

Fig. 4. ${ }^{239} \mathrm{Pu}$ activities of NIST prepared synthetic urine samples calculated from AMS measured ${ }^{239} \mathrm{Pu}$ atom contents of the submitted samples.

Fig. 5. Measured ${ }^{237} \mathrm{~Np}$ contents of the prepared samples compared to the expected ${ }^{237} \mathrm{~Np}$ content. Because of the observed difference in measurement system efficiency for $\mathrm{Np}$ isotopes compared to $\mathrm{Pu}$ isotopes, the plotted data have been normalized to the average value obtained for the sample containing $10^{10}{ }^{237} \mathrm{~Np}$ atoms.

Fig. 6. Measured ${ }^{236} U$ contents of the prepared samples compared to the expected ${ }^{236} U$ content. 


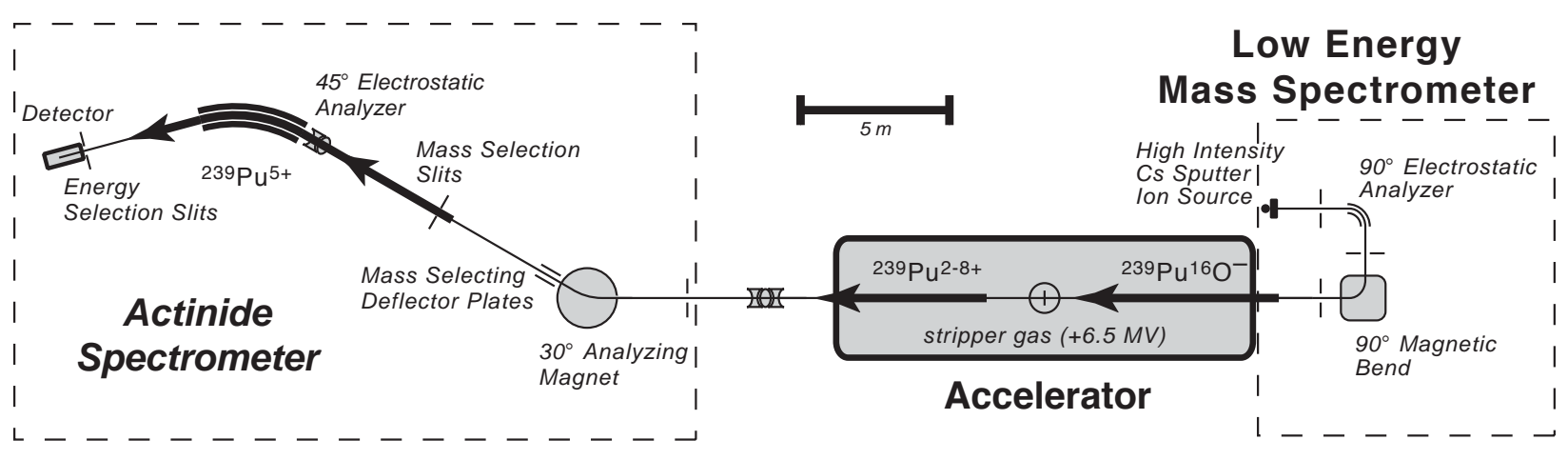

Fig. 1. AMS actinides measurement system at LLNL. The current system reflects the completion of Phase II of the system development. The isotope resolving capability of the high energy actinide spectrometer is provided by the analyzing magnet $\left(30^{\circ}\right.$ magnetic bend, image slits $4 \mathrm{~m}$ downstream) and the electrostatic analyzer (cylindrical, $4.4 \mathrm{~m}$ radius, $5 \mathrm{~cm}$ plate gap, $45^{\circ}$ bending angle, $50 \mathrm{kV} / \mathrm{cm}$ maximum field). 


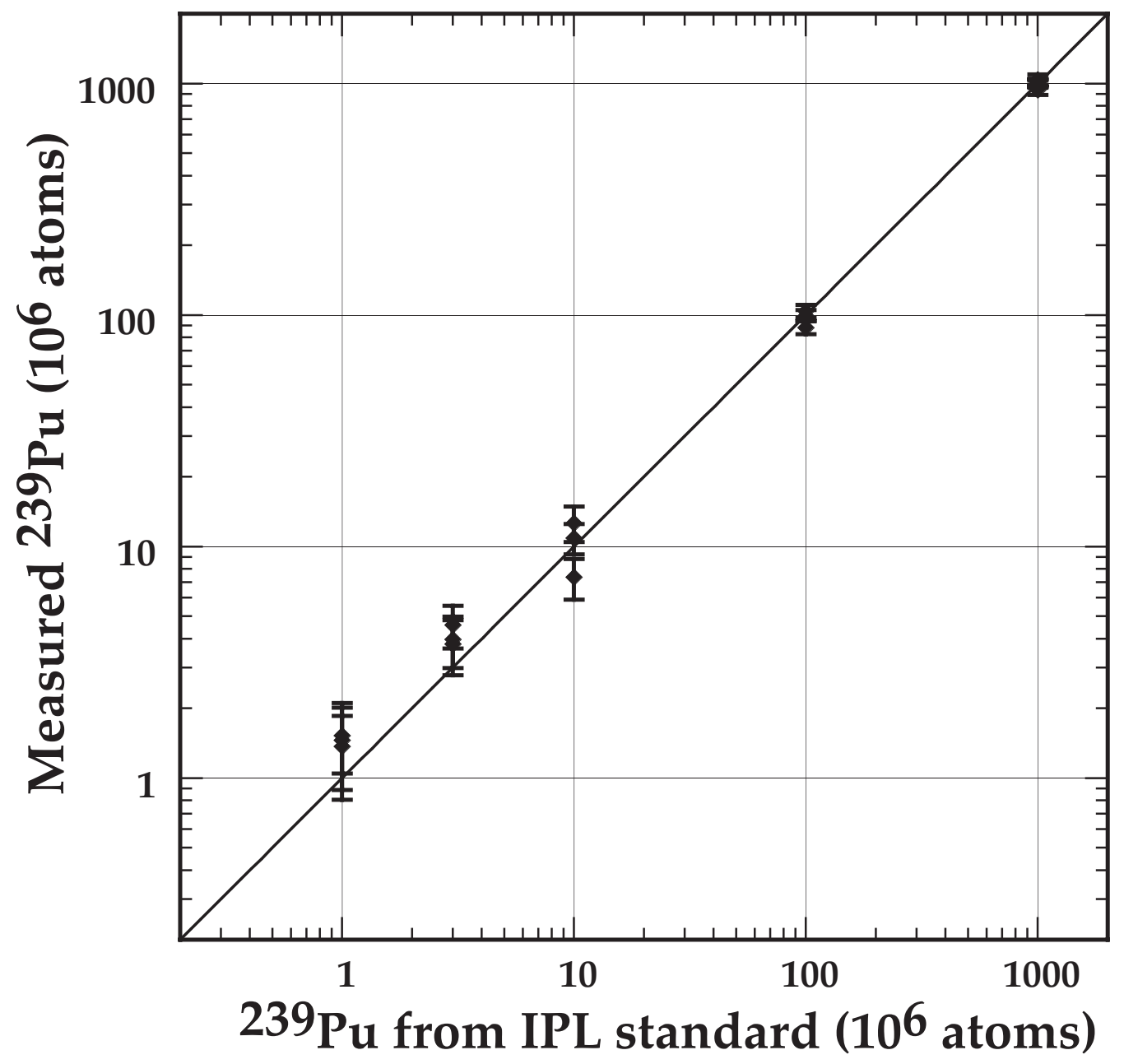

Fig. 2. Measured ${ }^{239} \mathrm{Pu}$ concentrations of a typical set of routine samples prepared from IPL 630-22-3. 


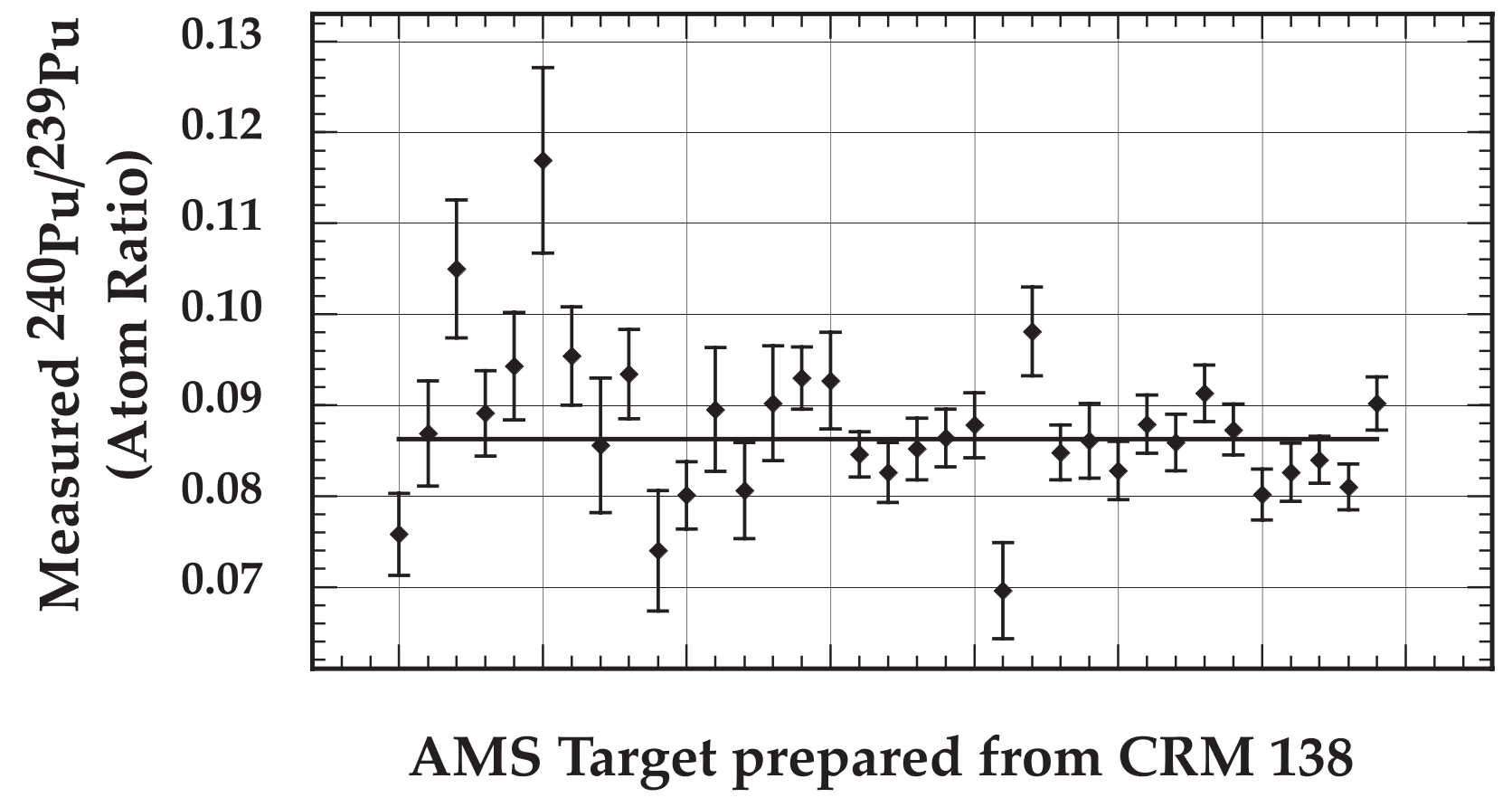

Fig. 3. Measured ${ }^{240} \mathrm{Pu} /{ }^{239} \mathrm{Pu}$ ratios of $35 \mathrm{CRM} 138$ samples prepared and measured between March and October, 2002 (horizontal solid line: certified CRM 138 atom ratio). 


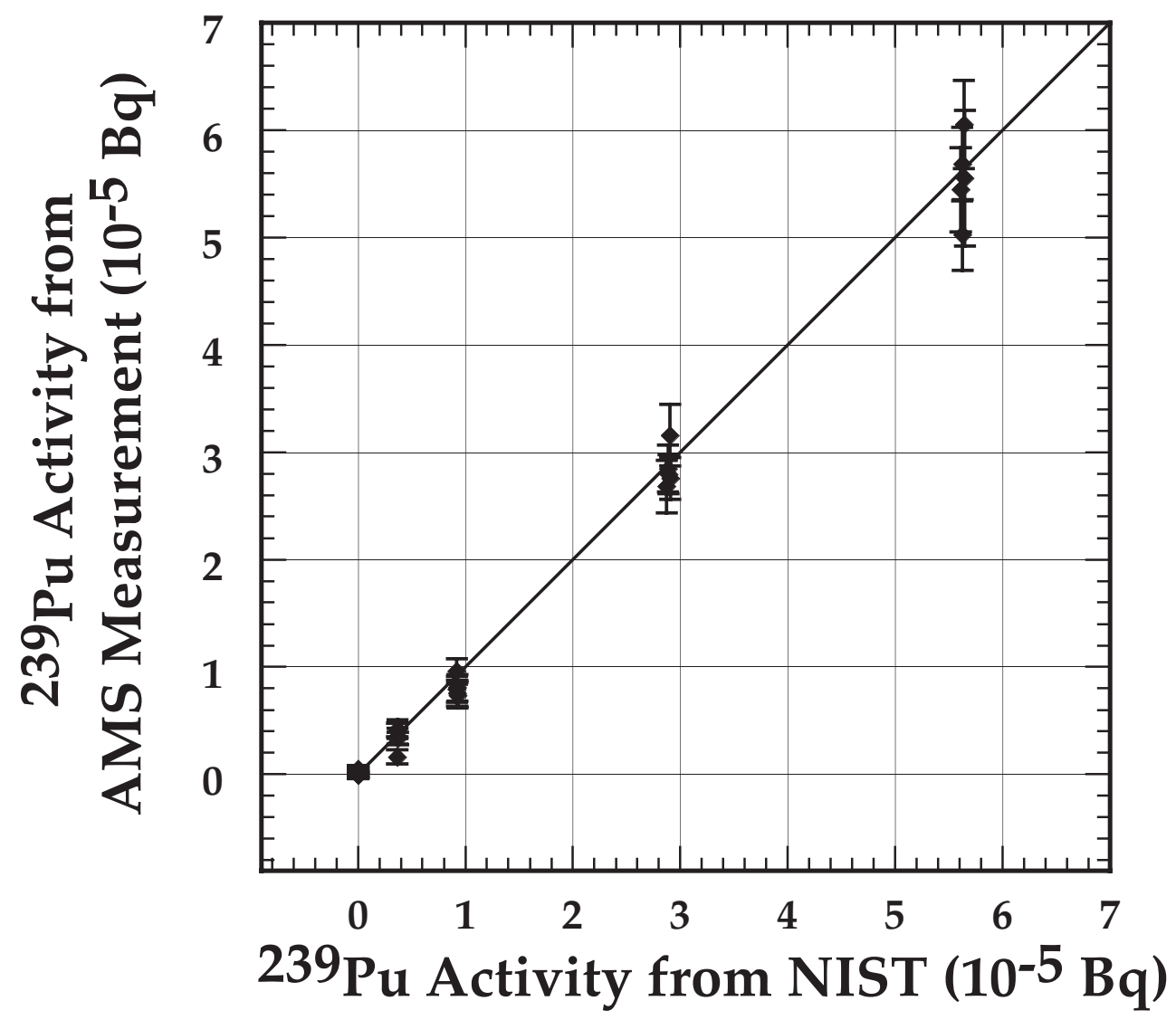

Fig. 4. ${ }^{239} \mathrm{Pu}$ activities of NIST prepared synthetic urine samples (calculated from AMS measured ${ }^{239} \mathrm{Pu}$ atom contents of the submitted samples) compared to the activities provided by NIST. 


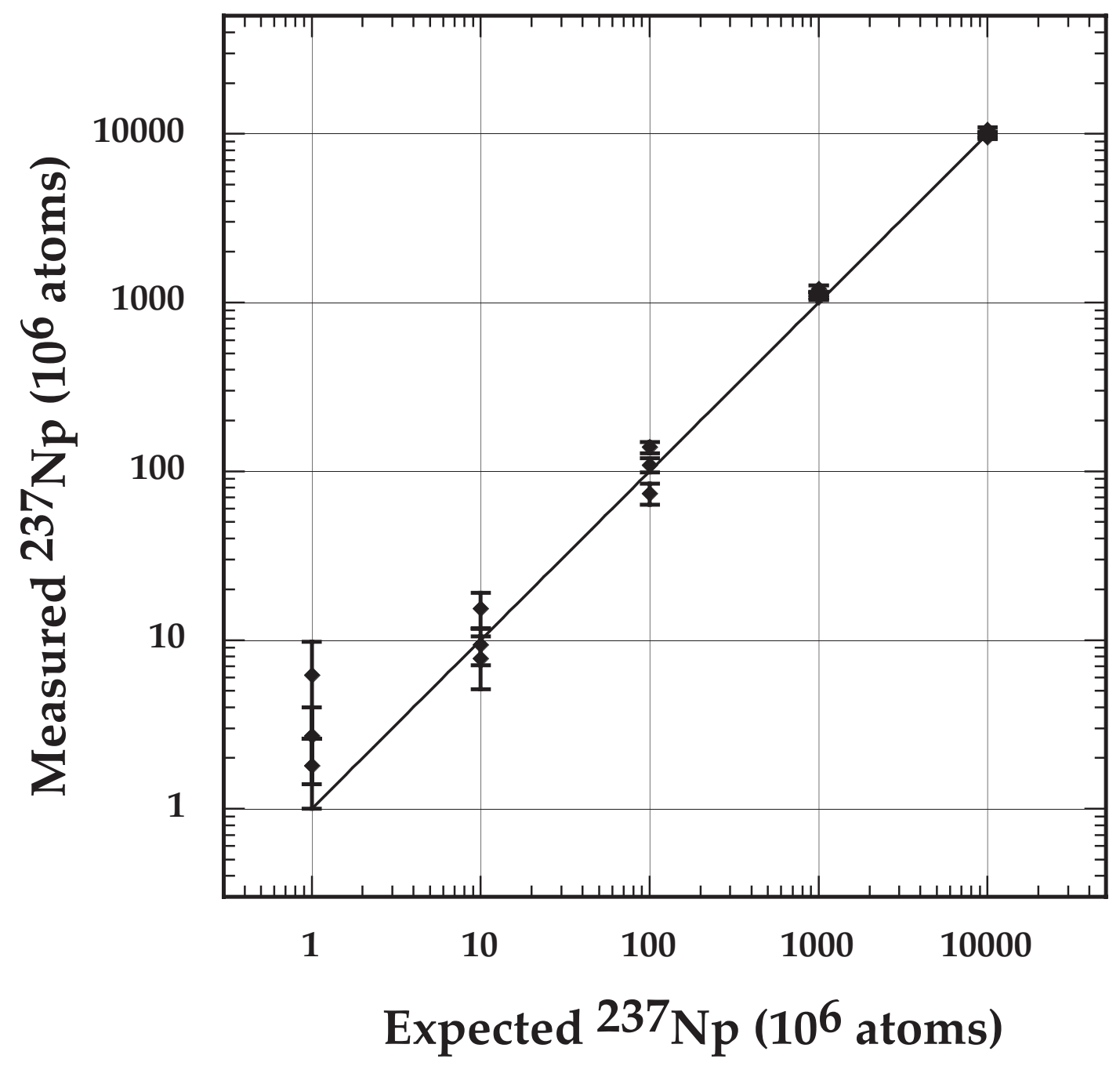

Fig. 5. Measured ${ }^{237} \mathrm{~Np}$ contents of the prepared samples compared to the expected ${ }^{237} \mathrm{~Np}$ content. Because of the observed difference in measurement system efficiency for $\mathrm{Np}$ isotopes compared to $\mathrm{Pu}$ isotopes, the plotted data have been normalized to the average value obtained for the sample containing $10^{10}{ }^{237} \mathrm{~Np}$ atoms. 


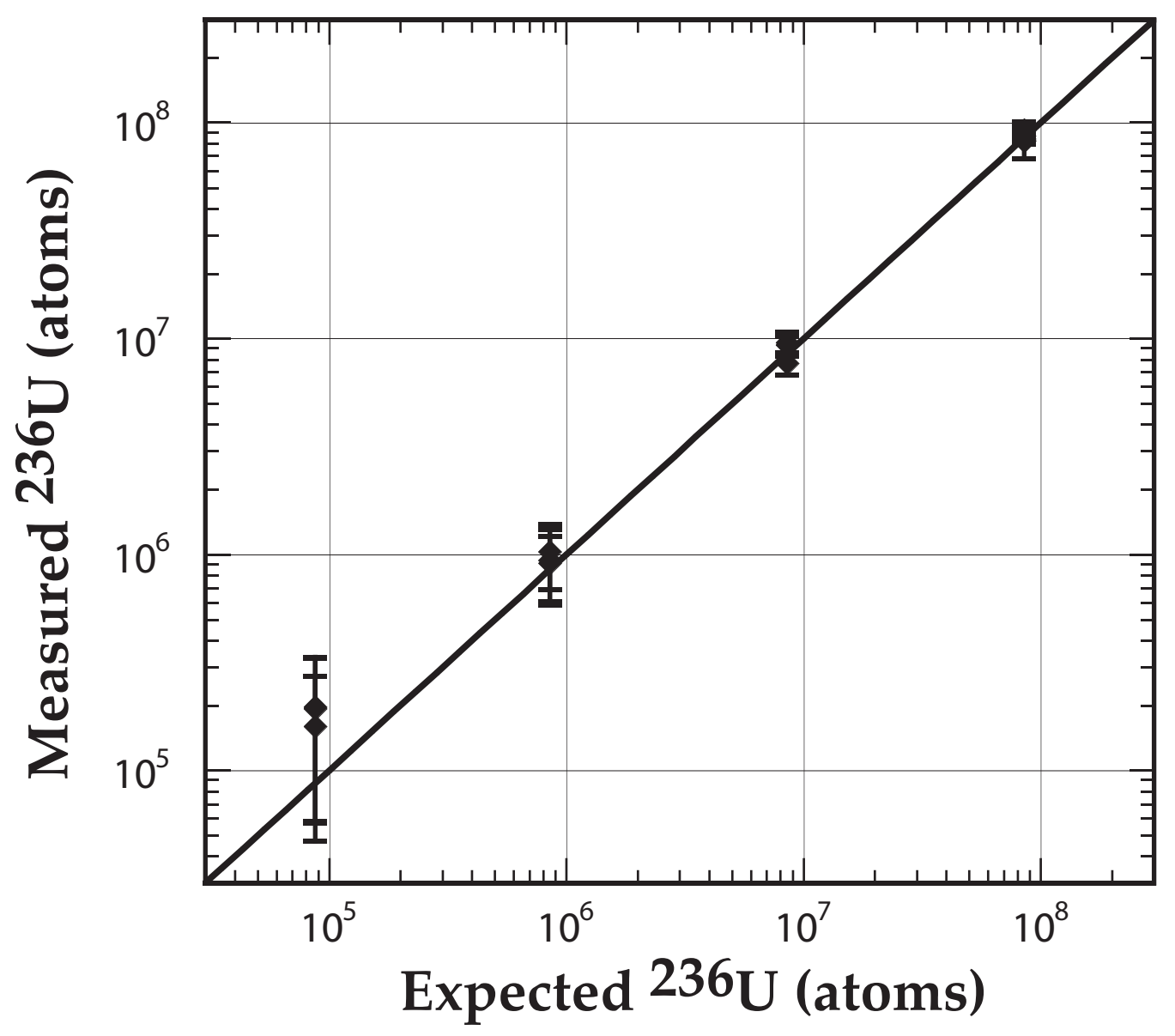

Fig. 6. Measured ${ }^{236} \mathrm{U}$ contents of the prepared samples compared to the expected ${ }^{236} \mathrm{U}$ contents. 